\title{
MUJERES EN LA PRENSA EN 1812
}

\author{
WOMEN IN THE PRESS IN 1812
}

Ma Jesús Soler Arteaga

Universidad de Sevilla

\section{Resumen:}

En una sociedad en la que la mujer tenía muy bien delimitado el ámbito de su actuación a la esfera de lo privado, encontramos varias mujeres que legitiman sus ansias de ocupar también el espacio de lo público, poniendo por escrito y, en definitiva, haciendo visibles sus pensamientos que podían tratar sobre cualquier tema, incluida la política. Estos textos vieron la luz en plena guerra de independencia, esta situación crítica propició que muchas mujeres tomaran un papel activo en la lucha contra la invasión napoleónica.

\section{Palabras claves:}

Mujeres, prensa, 1812, guerra de la Napoleonic invasion.

\section{Abstract:}

In a society in which women had very welldefined scope of their action to the sphere of the private, we found several women who legitimize their claim to occupy the public space, writing and making visible their thoughts that could treat on any subject, including politics. These texts saw the light during the War of Independence, this critical situation prompted many women to take an active role in the fight against the Napoleonic invasion.

\section{KEY WORD:}

Women, press, 1812, War of Independence, independencia, invasión napoleónica 


\section{INTRODUCCIÓN}

A lo largo de la historia del periodismo han sido escasas las ocasiones en las que las mujeres han desempeñado una labor reconocida al frente de una publicación periódica Sería necesario emprender un arduo trabajo casi arqueológico para desentrañar los nombres que el paso del tiempo ha ido soterrando. Trabajos tan importantes como el de Adolfo Perinat e Isabel Marrades que en su libro Mujer, prensa y sociedad en España. 1800-1939, intentan remontarse a siglos anteriores para establecer la tradición del periodismo femenino y solo pueden aportar dos nombres: Francisca de Aculodi y Beatriz Cienfuegos.

La primera de ellas, Francisca de Aculodi publicó en San Sebastian entre 1687 y 1689 Noticias principales y verdaderas. Se trataba de una publicación quincenal que reproducía una publicada en español en Bruselas y que alcanzó gran fama. La segunda de ellas, Beatriz Cienfuegos, será quien centrará inicialmente nuestra atención, por estar mucho más cercana en el tiempo al periodo histórico, que nos ocupa, y por tratarse de una publicación gaditana, como lo serán la mayoría de las que analizaremos en el presente trabajo. El nombre de Beatriz Cienfuegos ha despertado un enorme interés para la crítica. En diversas obras, como veremos seguidamente, los investigadores se hacen eco del problema de la autoría mencionando que no ha podido averiguarse si Beatriz Cienfuegos era su nombre real o un pseudónimo y lo que parece aún más atractivo para los investigadores, si fue una mujer o un hombre.

El disfraz del nombre tan indiferente para los antiguos irrita ahora la curiosidad pública por ser el único que oculta lícitamente el estado civil del escritor. Desvanecer ese incógnito es aclarar la historia literaria y hoy más que nunca útil, por ser tan usual el seudónimo en el periodismo, cada vez más extenso hasta el punto de haber empezado el siglo XIX publicándose en Madrid siete periódicos, según el cuadro grafico de los Apuntes para un catálogo de periódicos madrileños, de Don Eugenio Hartzenbusch, y existir a fin de siglo registrados en el Gobierno civil 420, según datos auténticos (Hartzenbusch, 1904: 7).

En la historia del periodismo, como señalaba José Fernández Bremón en la cita anterior, tomada del prólogo al estudio de don Eugenio Hartzenbusch e Hiriart sobre pseudónimos de escritores españoles, el encubrimiento del nombre real del autor ha sido una práctica habitual. Dicho estudio titulado Unos cuantos seudónimos de escritores españoles con sus correspondientes nombres verdaderos: apuntes recogidos y coleccionados por Maxiriarth se publicó con un pseudónimo del propio autor que jugaba con la autoría de un libro dedicado a desvelar el nombre real de numerosos escritores de la época. Además de esta afirmación se desprenden dos aspectos que deben tenerse muy en cuenta: en primer lugar la necesidad que surge de contextualizar toda producción y en segundo lugar que esta necesidad parece aún más útil en el caso de textos factuales puesto que en ellos hay o es esperable una mayor identificación entre autor-narrador.

El planteamiento de las hipótesis de diversos críticos y de los estudios llevados a cabo hasta el momento sobre la identidad de doña Beatriz Cienfuegos supone un punto de partida necesario, puesto que su identidad determina la perspectiva desde la que abordar el análisis de La Pensadora gaditana, periódico que comenzó a publicarse en julio de 1763, semanalmente, hasta julio de 1764. Durante ese año se publicaron 52 Pensamientos, que pueden situarse en la línea de crítica social y de costumbres, que había marcado el periódico inglés The Spectator dirigido por Addison Steele a principios del siglo XVIII. En esta misma línea en España La Pensadora fue coetánea de otras publicaciones como El pensador, El duende especulativo y El Censor.

En el caso de La Pensadora gaditana esta crítica se centraba especialmente en las costumbres femeninas, aunque se extendía a multitud de ámbitos, y alcanzaba a las costumbres masculinas y como ella indicaba, por tratarse de una mujer, con menor dureza y mayor objetividad que El Pensador:

Hasta que, exaltado todo el humor colérico de mi natural (que no es poco) con las desatenciones, groserías y atrevimientos del señor Pensador de Madrid, en orden a lo que trata de nuestro sexo, he resuelto tomar la pluma, no para contradecirle n do quile ni tacharle sus asung su idea, guardando sus máximas y aspirando a un mismo objeto) a criticar defectos sin ofender privilegios (Pensadora, v. I, 1786: 7-8).

Tanto en Inglaterra como en Francia hay constancia de una prensa escrita por mujeres, que se dedicaba a la crítica social, por lo tanto no tendría que resultar extraño que Beatriz Cienfuegos fuese realmente una mujer, sin embargo la crítica lo ha puesto frecuentemente en duda. En su obra Mujer, prensa y sociedad en España Adolfo Perinat e Isabel Marrades (1980:16-17) indican que La Pensadora representaba a una minoría ilustrada con la que no se identificaban la mayoría de las mujeres españolas, ni las nobles y burguesas ni por supuesto las campesinas y mendigas, por tanto concluyen que fue una anticipación del feminismo al tiempo que el inicio de la prensa femenina en España. Dicho esto, procederemos a mencionar las consideraciones de diversos críticos. Para Cotarelo, el autor es un hombre y además un eclesiástico, opinión que reproduce Antonio Palau y Dulcet en su Manual del librero hispanoamericano; igualmente Francisco Bravo en su artículo "Consideraciones sobre la mujer en dos periódicos gaditanos

1 En nuestro trabajo citamos la reedición de La pensadora gaditana hecha en 1786 por la imprent de Manuel Jiménez Carreño en Cádiz, puesto que la colección completa puede consultarse en la biblioteca de la Universidad de Sevilla, en la biblioteca de la Universidad de Cádiz, que ofrece la posibilidad de consulta online del texto digitalizado. Así mismo puede consultarse la edición original de 1763-64, la reedición que realizó Cinta Canterla en 1996, en la que aparecen 17 de los 52 pensamientos, y la que realizó Scott Dale en 2005, que reúne en su libro los cuatro volúmenes de Pensamientos, modernizando la ortografía. 
del siglo ilustrado: La Pensadora gaditana y la Academia de ociosos" recoge la afirmación vertida en Diario Mercantil del 3-10-1820, en la que se indicaba que Beatriz Cienfuegos escondía el nombre de D. N. del Postigo. También es importante la aportación de Eugenio Hartzenbusch que reproduce en su libro Apuntes para un catálogo de periódicos madrileños: desde el año 1661 al 1876, ${ }^{2}$ se trata de la indicación de Nicolás María de Cambiaso en la que indicaba que no había podido encontrar ninguna referencia en los libros de la catedral pero se hacía eco de algunas opiniones sin mencionar ningún nombre según las cuales para algunos la autora se había cambiado el nombre, para otros había cogido el apellido de su madre y para otros podría ser un escritor con velo de mujer.

Frente a estas opiniones, Ramón Solís en su obra Historia del periodismo gaditano afirma que se trata realmente de una mujer; Cinta Canterla que ha estudiado ampliamente esta cuestión, y que realizó una edición antológica de la publicación, indica que es una mujer y que firma con su nombre apoyándose en dos aspectos importantes: en primer lugar en la existencia del apellido en Sevilla y en América, y en segundo lugar en que la legislación de la época prohibía publicar libros o papeles con nombre falso, y la publicación contaba con licencia de impresión, por lo tanto deduce que el nombre debía ser real, en caso contrario los censores no habrían concedido la licencia. En estos mismos argumentos se basa para decir lo contrario Scott Dale en su obra en la que incluye un estudio y la reedición de toda la obra, puesto que considera definitivos la falta de documentos oficiales en los que se pueda comprobar la existencia real de doña Beatriz, las dificultades que habría tenido en la época una mujer para conseguir la licencia de impresión y por último la aportación del Diario Mercantil en el que se atribuía la autoría a D. N. del Postigo. Por otra parte S. Dale (2005: XIII) refuta la posibilidad de que el autor fuera Cadalso como han apuntado algunos investigadores, apoyándose en una carta de Francisco Aguilar Piñal dirigida personalmente a él en la que indicaba que la relación entre Cadalso y La pensadora gaditana era incierta. Para el investigador norteamericano Beatriz Cienfuegos es uno de los pseudónimos utilizados por don Juan Francisco del Postigo que publicó en la misma imprenta y vendió en la misma librería La pensadora gaditana y un año después Combates de amor, publicado también bajo pseudónimo, en este caso D. Fernando Jugaccis Pilotos, aunque para S. Dale las semejanzas no son meramente circunstanciales, sino que también coinciden en: "la equivalente singularidad en el lenguaje, estilo, vocabulario y acercamiento de la voz narrativa en la advertencia de Combates de amor y en los cuatro tomos de $\mathrm{La}$ pensadora gaditana" (Dale, 2005: XX).

2 Cinta Canterla (1996) indica que fue considerado como un periódico madrileño en algunos catálogos debido a la existencia de dos ediciones, la primera en Cádiz (los 26 primeros pensamientos) y la segunda en Madrid), en ocasiones aparecen encuadernados juntos pensamientos editados en Cádiz junto con los de Madrid y por ello se ha catalogado como una edición madrileña.
En medio de estas averiguaciones nos encontramos con el artículo de Constance Sullivan publicado en la revista Dieciocho, titulado "Gender, text, and cross-dressing: the case of Beatriz Cienfuegos and La pensadora gaditana", en el que da por hecho que se trata de un autor que crea un personaje femenino y para ella esto resulta lo más interesante: "In this regard, La Pensadora Gaditana is a fascinating case. It is an eightieenth-century performance of femaleness by a male autor who creates a female persona and voice for himself in the text, while sprinkling the publication simultaneously with features that contradict or undermine the authenticity of that female identity" (Sullivan, 1995: 28). ${ }^{3}$

3 Hay argumentos, como puede verse, tanto para apoyar la creencia de que se trata de una mujer, como para apoyar que se trata de un hombre; pero sin que podamos decir que ninguno de ellos es definitivo. Por todo ello sería conveniente volver a revisar lo que la propia Pensadora dice de sî misma en el Pensamiento I, que sirve de prólogo a la obra:

Ya sale a campaña una mujer que las desempeñe y en fin con pluma y basquiña con los libros y la bata se presenta una Pensadora que tan contenta se halla en el tocador como en el escritorio, igualmente se pone una cinta que ojea un libro... (Pensadora, v. I, 1786: 5).

Yo señores gozo de la suerte de ser hija de Cádiz: bastante he dicho para poder hablar sin vergüenza. Mis padres desde pequeña, me inclinaron a monja, pero yo siempre dilaté la ejecución. Ellos porfiaron y para conseguir el fin de sus intentos me enseñaron el manejo de los libros y formaron en el buen gusto de las letras (Pensadora, v. I, 1786: 9-10).

En estos dos fragmentos podemos observar dos aspectos sobre los que abunda a lo largo de este prólogo, y en otros Pensamientos: en primer lugar se muestra orgullosa de ser mujer y gaditana; y en segundo lugar justifica su amplio bagaje cultural. En cualquiera de los 52 Pensamientos llaman la atención del lector las continuas referencias a los clásicos greco-latinos y las citas en latín con las que suele introducir los poemas con los que terminan casi todos los Pens y lantos: so los y octavas, en su mayoría, que ponen de manifiesto su habilidad para versificar; habilidad que desciende de los temas clásicos para fijarse en realidades prosaicas como la moda. Este hecho que podría inclinarnos pensar que en realidad se trataba de un hombre dada la escasa formación que recibín las mujeres de la época tampoco es definitivo como subraya Constance Sullivan en el artículo anteriormente citado dado que también hubo mujeres con un alto grado de erudición, entre ellas algunas monjas, la autora americana cita a María del Rosario Cepeda, María Isidra Cuzmán de la Cerda Josefa Amar y Borbón,

Sin embargo Doña Beatriz va más allá, puesto que ella misma nos da la clave para decir que tal vez La Pensadora gaditana fuese una mujer; pero no respondió jamás al nombre de Beatriz Cienfuegos, y lo hace al comienzo del Pensamiento IV, en el que se extiende sobre este asunto y que precisamente trata del tapado en la mujer: "No se cansen, es trabajo perdido; que no soy tan tonta que no tomase muy bien las medidas para ocultarme antes de dar al público mis Pensamientos... Conténtense Vms. con saber que la Pensadora es mujer (que lo es cierto), que las demás circunstancias discurro que no son precisas para la aceptación de mis Discursos: ellos solos serán los que se hagan su fortuna" (Pensadora, v. I, 1786: 65-66).

No era ajena la Pensadora, como queda de manifiesto en estos fragmentos, al interés y las dudas que despertaba en su época su identidad, aunque esta cuestión a la vista de lo expuesto resulta de difícil solución. Tal vez el estudio de la prensa de la época sería de gran utilidad, ya que sus pensamientos no debieron pasar inadvertidos para esta; puesto que en cada uno de sus pensamientos exponía su opinión: sobre las costumbres de la época, y no dudaba en criticar a sus congéneres y a los hombres. Además de ser consciente de la curiosidad que debía despertar en sus lectores, emplea bastante a menudo un recurso que no pasa inadvertido para la crítica y es el hecho de que la autora crea a sus propios lectores y sobre todo a sus lectoras que no se contentan con leer sus pensamientos sino que le escriben convirtiendo sus misivas en pensamientos prestados a otras voces femeninas y en palabras de Constance Sullivan empleando una y otra vez el recurso del "travestismo literario" 
En cuanto al estilo y adscripción genérica, nos encontramos ante un tipo de prensa muy próximo a la literatura, que era corriente en la época. Como acabamos de decir no solo la Pensadora es un personaje inventado por alguien que quiere ocultarse tras esa máscara sino que inventa otros personajes para mantener la ficción de la existencia de lectores con los que se comunica y que al ser ella misma le permiten exponer desde otro ángulo un tema que la Pensadora deseaba tratar. Principalmente en estos 52 “Pensamientos” predomina el estilo ensayístico, y tiene cabida la creación literaria y poética, puesto que muchos de sus pensamientos llevaban un poema que servía de resumen y colofón del pensamiento. Albert Chillón (1999: 132) señala en su libro Literatura y periodismo la vinculación del ensayo con la prensa de opinión se sitúa en el siglo XVIII y añade que: "sirvió como vehículo para la polémica y la discusión". Para Perinat y Marrades sus textos se caracterizan por estos dos aspectos: "Predomina un estilo personificado y, próximo al epistolar, más propio del diálogo cara a cara que de los sistemas de difusión hacia la masa anónima" (Perinat y Marrades, 1980: 64).

Ese estilo personificado es fácilmente constatable puesto que en todo momento habla en primera persona y se dirige a sus lectores en plural o en singular, dependiendo de si contesta, o no, a una pregunta formulada por un lector; y además se trata de su opinión puesto que se ha erigido en censora de las costumbres. Por otro lado puede calificarse como feminista, como así lo hacen Perinat y Marrades, en tanto que se preocupa por la formación y la educación de las mujeres; y que al menos para ella misma rechaza las ataduras del matrimonio, como indica en el Pensamiento I: "Mi inclinación es la libertad de una vida sin la sujeción penosa del matrimonio." (Pensadora, v. I, 1786: 11). De estos 52 Pensamientos hay 18 que se presentan como cartas enviadas por los lectores en las que se desarrolla un asunto y se pide a la Pensadora que dé su parecer sobre el mismo, correspondencia a la que invita doña Beatriz en el Pensamiento VIII, pese a que ya el VII era una carta: "Advertencia. En las librerías donde estos pensamientos se venden, podrá el que gustare de escribirme entregar las cartas; que como no pasen de dos pliegos, y sean asuntos decentes se imprimirán" (Pensadora, v. I, 1786: 183)

\section{Dos Mujeres en la PRensa gaditana De 1812}

La pensadora gaditana, como puede deducirse de lo expuesto anteriormente, fue una de las más importantes precursoras del periodismo femenino e incluso una anticipación sui generis del feminismo, salvando lógicamente las distancias. Las leyes que regían la prensa no eran favorables, y dificultaron que tuviera continuadores, de hecho en

This reiterative defensiveness, or flamboyant reassertion, concerning the femaleness of the autor perhaps reflects real doubts in the reader response in the Madrid of 1763 (at the risk of stating the obvious: "Beatriz Cienfuegos" invents her textualized readers), but it also functions to the keep the question of gender identity in the foreground of the journal's discourse, and forces reads to look again and again at the cross-dressed figure (Sullivan, 1995: 33).
1795 El diario del Bello Sexo vio cómo Carlos IV denegaba la autorización para publicar y no será hasta 1822 cuando aparezca El periódico de las Damas dedicado íntegramente a las modas. Además será necesario esperar a las décadas de los 40 y 60 para encontrar periódicos como La moda elegante, en los que tendrán cabida las colaboraciones de $\mathrm{M}^{\mathrm{a}}$ Pilar Sinués, Robustiana Armiño o Gertrudis Gómez de Avellaneda. Ramón Solís en su obra Historia del periodismo Gaditano 1800-1850 da cuenta de los rigores de la censura de la época y constata que fueron más acusados en Cádiz que en otras ciudades, de hecho relaciona las vicisitudes por las que pasaron distintos autores que quisieron conseguir permiso para publicar un diario sin conseguirlo debido a la oposición de la censura gubernativa que dio todo tipo de excusas para no conceder la licencia pertinente. Finalmente el primero en conseguirla fue el Barón de la Bruere para publicar el Diario mercantil, aunque se trató sin lugar a dudas de un premio a su constancia, puesto que durante nueve años insistió para que se la concedieran.

Sin embargo durante la guerra de la independencia esta situación va cambiando y si en los años anteriores a las Cortes los periódicos tienen un marcado carácter literario, junto a los artículos aparecían noticias de actualidad, durante el periodo que nos interesa se produce en Cádiz el nacimiento de la prensa política. Todo ello hace que sea una etapa extraordinariamente interesante y aunque el periodismo en el siglo XVIII es un género que no ha sido completamente estudiado y en el que existen numerosas lagunas, algunos trabajos de investigación están contribuyendo a paliar esta situación. Un ejemplo de ello son los trabajos de Beatriz Sánchez Hita, Marieta Cantos Casenave, Alberto Romero Ferrer, etc.

En el interesante artículo de Beatriz Sánchez Hita “La imprenta en Cádiz durante la Guerra de la Independencia y su relación con la prensa periódica” cita la existencia de numerosos imprentas en la ciudad de Cádiz en este periodo, entre las que se mencionan las de Jiménez Carreño y la de Guardias Marinas, en ambas se imprimieron Los Pensamientos de Beatriz Cienfuegos, y constata el aumento de las mismas a partir de 1790. Así mismo, menciona la existencia de veinte librerías y de dos tiendas de encuadernación. Con estos datos da pruebas más que suficientes de que existe una infraestructura consolidada en la ciudad. Además era requisito indispensable que apareciera en la prensa de la época la periodicidad y la información sobre las librerías en las que podían adquirirse estas publicaciones para no perder lectores, ya en $L a$ pensadora gaditana se daba puntual cuenta de estos detalles para que sus lectores supiesen dónde podían dirigirse no solo para comprarlos sino también para enviar sus cartas.

Todos estos datos deben considerarse como pruebas no solo de la existencia de una infraestructura suficiente y necesaria para la impresión y difusión de la prensa local sino también como pruebas de la existencia de un público interesado en leer estas 
publicaciones, más aún si tenemos en cuenta que Cádiz era en las fechas a las que nos referimos un importante enclave económico y comercial, puesto que había desplazado a Sevilla como principal puerto en el comercio con las Indias, con todo lo que ello suponía. A todo esto debemos sumar un hecho de gran relevancia, en noviembre de 1810 se decreta la libertad de prensa, gracias a la cual surgen numerosas publicaciones periódicas. Una vez eliminadas las trabas que impedían el normal funcionamiento y debido a las especiales circunstancias en las que se encontraba el país en aquellos momentos la prensa se convierte en un "arma política", así lo reconoce Ramón Solís en su obra, puesto que las Cortes daban por primera vez soberanía al pueblo, pero éste desconocía las cuestiones más elementales y los periódicos debían informar y aclarar las actuaciones, decisiones y opiniones de los diputados, convirtiéndose en ese instante no en publicaciones de carácter literario o económico, como habían sido hasta ese momento, sino que su temática principal sería entonces la política.

El conflicto por sus especiales características propició que la sociedad interviniera activamente y debido a esta implicación se produjeron importantes cambios sociales. Las mujeres no fueron ajenas a todo esto, por otra parte la necesidad de que las mujeres, debido a los estragos de la guerra, tomaran parte en la vida pública fue un hecho. Alberto Ramos en su estudio "La vida cotidiana en el Cádiz de las Cortes" constata la implicación de las mujeres en aquellas actividades que por su sexo resultaran más apropiadas, así en el Diario mercantil de Cádiz del 1 de julio de 1808 se recogen noticias en las que se resalta la colaboración de algunas mujeres que se habían ofrecido a elaborar ropa para el ejercito, indicándose que estaban dando prueba de patriotismo. Así las mujeres colaboraron recaudando donativos, recogiendo ropa, cosiendo, etc. Además el Diario mercantil "se hizo eco del Bando en el que la junta suprema había ordenado, el 6 de junio, que las mujeres colaboraran en la guerra trabajando en la agricultura, y aquellas que no pudieran por razones de edad o debilidad de complexión, se dedicaran a hacer vendas y otras telas útiles para los hospitales" (Ramos, 2008). Estas peticiones concretamente dieron lugar a la creación de la Junta de Damas de Fernando VII en Cádiz.

Nuestro interés a partir de este momento se centrará en dos figuras femeninas de gran importancia en la época, puesto que tuvieron una participación destacada en periódicos de contenido político y bastante combativos contra la invasión napoleónica. Como hemos visto al inicio de nuestro trabajo, estos no son los primeros casos de mujeres que intervienen en la prensa, pero el conflicto y las circunstancias particulares de cada mujer propiciaron que su presencia en los periódicos fuera mayor.

En estas páginas dedicaremos nuestra atención a la producción de Ma Manuela López de Ulloa y Carmen Silva que por la especial relevancia de sus producciones en distintos medios de la época merecen un estudio detenido. Se conocen pocos datos de sus biografías, sin embargo aquí mencionaremos los que nos resultan más destacados en relación a su producción que seguidamente pasamos a analizar.

\subsection{M..$^{\underline{a}}$ Manuela López de Ulloa}

Es frecuente que escaseen los datos biográficos de las autoras de esta época, puesto que su producción no siempre fue suficientemente valorada y porque a menudo han caído en el olvido. El caso de M ${ }^{a}$ Manuela Vázquez Ulloa no solo no resulta una excepción sino que además no existen prácticamente datos sobre ella. Los únicos testimonios que han quedado de su labor como escritora se encuentran en la prensa de la época y el acceso a estas publicaciones se ve dificultado aún más, puesto que se encuentran en hemerotecas y salas de difícil acceso que solo se está viendo paliado por las digitalizaciones de algunas instituciones y por los magníficos trabajos realizados recientemente por investigadores que están dedicando su esfuerzo a una tarea sin duda necesaria para sacar a la luz la figura y obras de las mujeres de este periodo. ${ }^{4}$

Entre los pocos datos que podemos aportar sobre esta autora, diremos que fue manchega, que más tarde debió pasar a Sevilla y luego a Cádiz, siguiendo a los diputados que habían permanecido fieles a Fernando VII. Su participación en los periódicos se prolongó durante varios años, después de esto desaparece del panorama literario y periodístico, así lo señala Marieta Cantos Casenave en sus trabajos. Las colaboraciones firmadas de M. ${ }^{a}$ Manuela López de Ulloa comienzan el 24 de diciembre de 1812 con un artículo que apareció en El Procurador General de la Nación y del Rey, se trataba de un periódico de corte político, antirreformista y como señala R. Solís (1971: 78) se produjo un gran escándalo cuando se supo que recibía dinero de la regencia.

En su artículo la autora se defiende de los insultos recibidos en otro periódico. Seguir el hilo conductor de estas publicaciones en las que se cruzan opiniones y también insultos contra la autora, que firmaba el artículo como M.L., ocupará parte de nuestro trabajo:

Muy Sr. mío. En El Redactor general núm. 538, leí una quintilla cuyo sentido me inquietó sumamente (como me sucede con la mayor parte de los artículos de este Periódico) y a fin de tranquilizar mi espíritu y desahogar los sentimientos de mi corazón, tomé la pluma, y con una ligera variación que la di repentinamente, aunque con ánimo de glosarla más despacio, trunqué su sentido y la remití a $\mathrm{V}$. aunque con ánimo de glosarla más despacio, trunqué su sentido y la remití a $V$. pp. 681).

4 Entre estos trabajos debemos resaltar los estudios de Beatriz Sánchez Hita, Marieta Cantos Casenave, Elisa Martín-Valdepeñas Yagüe, Irene Castells Olivan, Elena Fernández García, Jesús López de Lerma y Galán o Blasina Cantizano Márquez. 
La quintilla a la que se refería aparecía en el número 538 de El Redactor general en una sección titulada Impresos, en la que se destacaban colaboraciones aparecidas en la prensa del día anterior, concretamente se cita el Diario mercantil del 2 de diciembre de 1812 y se menciona un epigrama de J. F.: “Con impío corazón / querer a un hombre arruinar / socolor de religión, / solo lo puede intentar / quien quiera la inquisición. En la entrega 70 de El Procurador General fechado el 9 de diciembre de 1812 apareció el mismo epigrama y tras este, según se indica en el texto: “Reverso formado por una señora":

$$
\begin{aligned}
& \text { Con impío corazón } \\
& \text { Querer a un hombre salvar } \\
& \text { Traidor a la Religión, } \\
& \text { Solo lo puede intentar } \\
& \text { El Hereje o Francmasón. } \\
& \text { Décima } \\
& \text { No extrañe el Procurador } \\
& \text { De la nación y del Rey } \\
& \text { Que, sin caridad ni ley, } \\
& \text { Le calumnie el Redactor: } \\
& \text { La ciencia de este hablador, } \\
& \text { Y de toda su hermandad } \\
& \text { Es la de la iniquidad; } \\
& \text { Es la de la irreligión } \\
& \text { Y es la de hacer la Nación } \\
& \text { Sierva de su libertad. }
\end{aligned}
$$

La respuesta no se hizo esperar al día siguiente, el 10 de diciembre en El Redactor General en la misma sección de impresos se destacan las coplas y se cargan las tintas contra la autora de las mismas, si la conocía o no quien se encargaba de la sección no podemos asegurarlo, aunque es probable que se supiera quién colaboraba con los periódicos firmara o no. En su extracto dice: "Siguen unas coplas al Redactor 538, por una marisabidilla o marisabijonda (según sea, más o menos pandorga), la cual cotorrea contra el hereje y francmasón, dejando a un lado la labor y la almohadilla por los braseros inquisitoriales, a que se muestra un tanto cuanto aficionada esta culti-latini-parla. ¡Pobre señora! ¿Quién la habrá metido a teóloga? ¿Si será su director espiritual el Procurador?" (El Redactor General, 1812: no 545, pp. 2179). Tras estas palabras la ofendida escribe el artículo del día 24 de diciembre en el que se descubre a sí misma como autora de los versos anteriores y se muestra ofendida por sus palabras, en las que como vemos se emplean los insultos tradicionales, haciendo referencia a la falta de conocimientos o el exceso de los mismos en una mujer, debemos recordar la escasa formación que se daba a las jóvenes de la época:

Yo estaba muy ajena de pensar, que los mal formados rasgos de una mujer sirviesen de asunto a las bufonadas, sarcasmos y ridículas ironías del Redactor general, pues siempre ha sido respetado nuestro sexo, entre personas de buena crianza y aún de las más rústicas: pero quedé admirada cuando en el núm. 545 del citado periódico, leí las zumbas y satíricos refranes con que intenta zaherirme. El estilo chocarrero que usa, las groseras y chabacanas expresiones, más propias de un mesón o taberna que de un papel de ilustración, me dan la más clara idea de la oscuridad de sus autores (El Procurador General, 1812: no 85, pp. 681-682).

El texto no deja lugar a dudas sobre la autoría de los citados versos, puesto que indica que en ese texto intentaba zaherirla y más adelante indica que sus ocupaciones domésticas no le han permitido hasta la fecha escribir la glosa que seguía al texto en prosa firmándolo con las iniciales M.L. Estas quejas de la autora y la referencia a sus quehaceres nos recuerda inevitablemente a La Pensadora gaditana cuando decía: "Ya sale a campaña una mujer que las desempeñe y en fin con pluma y basquiña, con libros y bata se presenta una Pensadora, que tan contenta se halla en el tocador como en el escritorio, igualmente se pone una cinta que ojea un libro" (Pensadora, v. I, 1786 5-6). Será también el mismo tono que seguiremos encontrando pasado el tiempo en otras autoras, por ejemplo en Carolina Coronado y su poemario "La poetisa de un pueblo", la misma sensación de ser juzgadas por su condición de mujer más que por sus palabras.

Obviamente la respuesta no se hizo esperar, el día 25 de diciembre en El Redactor se daba una respuesta en la que se atacaba de forma bastante más agresiva a Manuela López diciendo que estaba muy "picadita", que no sabía versificar y añadía:

y hace una glosa o glosario de una quintilla del R. 538, que la inquietó mucho a la pobrecita, según costumbre. El Redactor (aunque no es caballero al gusto de esta licurga, que muestra aficioncilla a los tontillos y anchurosos atavios de los tiempos de antaño, y que se da por satisfecha de andar a la par de los obispos) sentiría que esta quintilla hubiese indispuesto a tan melindrosa y mojigata dama, y que se siguiese algún fatal accidente; y más, si por casualidad estaba encinta... ioh Dios Santo! iqué dolor, si la quintilla la hici General, 1812: n. 560, pp. 2240).

Las siguientes colaboraciones las encontramos en tres entregas del mes de febrero La primera en 7 de febrero en la que seguía respondiendo a las palabras anteriores, la polémica suscitada por las consabidas quintillas duró unos meses. En ésta, la autora también responde, aunque esta vez mostrándose más altiva que ofendida:

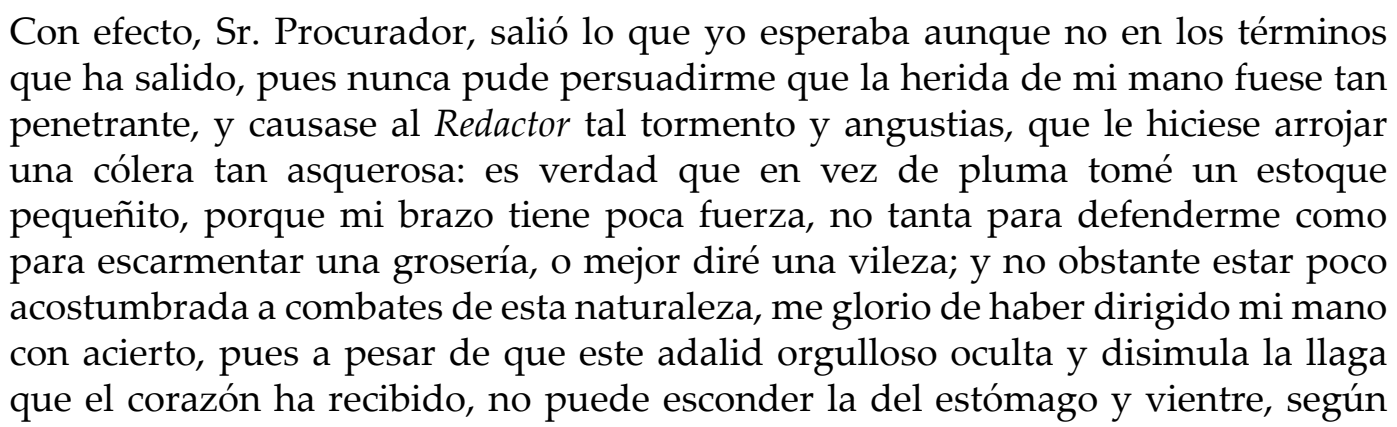


las suciedades que arroja en su núm. 560 (El Procurador General, 1813: n.ํำ 130, pp. 1061)

En el fechado el 12 de febrero responde a un artículo titulado "Leer con tiento", publicado en el mismo periódico. En su texto Manuela López considera que la lectura que hace el autor de las doctrinas de Maquiavelo no es acertada y cita como autoridad al Padre Feijoo, lo que demuestra que los ha leído a ambos y conoce sus textos y finalmente parece refugiarse en el tópico de la "captatio benevolentia": "Bien conozco Señor Procurador, que el asunto que me he propuesto es demasiado arduo para la débil mano de una mujer que no ha tenido estudios, ni más principios que una educación sencilla" (El Procurador General, 1813: n.․ 135, pp. 1111-1112). En la entrega del 23 de febrero criticaba abiertamente un artículo de Mexía en el que censuraba a la inquisición por haber excomulgado a algunos reyes a los que consideraba víctimas de la inquisición y ella se preguntaba si verdaderamente podía considerarse a Enrique IV o a Federico II víctimas. Además le rogaba al editor que publicara el texto si no le importaba incluir en su diario las palabras de una mujer que despreciaba las ridículas befas y sarcasmos de los periodistas.

En esta misma línea continúa en el texto publicado el 22 de agosto de 1813 en el que cargaba las tintas contra La Abeja Española, publicación de corte liberal, a la que se refería con estas palabras: "esta abejita nueva, apenas sale de su avispero quiere trastornar el orden con sus zumbidos, y a pretexto de libertad e independencia intenta sublevar a las pacíficas y oficiosas compañeras que gobernadas por sus reyes, están en sus vasos o corchos vecinos clavando su aguijón donde halla resistencia, solo se ocupa con los zánganos que la acompañan en comer la miel que usurpa, y aniquilar su propia colmena" (El Procurador General, 1812: n.o 326, pp. 3673-3674). El texto era tan largo y tenía tantas objeciones contra La Abeja Española que al día siguiente se publicó en el mismo periódico la continuación del artículo, como vemos nuestra autora tampoco duda en atacar decididamente a otros autores y publicaciones.

Muy interesante es el número 102 fechado el 17 de abril de 1814. A lo largo de este artículo reflexiona sobre las opiniones vertidas en El Duende de los cafés, el que se interpretaba una carta del rey Fernando VII. En ese diario se le comparaba con Luis XVI y nuestra autora que era una monárquica convencida muestra aún su confianza y lo compara con el bíblico rey David que venció a Goliat. El 4 de agosto de ese mismo año publicó otro texto defendiendo al rey, en esa ocasión se hace eco de una noticia que se ha publicado referida a los prelados que estaban rechazando puestos por no estar de acuerdo con la vuelta del rey. Ella indicaba que no debía ser así, que tenían que aceptar porque ese esfuerzo se hacía por la nación. Además indicaba que había estado un mes de viaje en La Mancha y que volvía decidida a dar su parecer con respecto a todos los asuntos de actualidad. En ese mismo año sus colaboraciones aparecieron en un periódico de la capital La Atalaya de la Mancha, como indica Marieta Cantos Casenave con el seudónimo "La española en la Corte", en los que trata de nuevo diversos temas especialmente alabanzas hacia Fernando VII y críticas bastante divertidas como la que aparece en la entrega del 4 de marzo de 1813, en la que explica un proyecto económico que consiste en poner un criadero de gallinas con espacio para doscientas gallinas en la ciudad de Sevilla, proyecto ideado por el Sr. Intendente Flores de Estrada con dinero público y que resultaría insalubre para los vecinos y del que se detallan los aspectos más repugnantes. En otro de ellos, publicado el día 2 de abril se dirigía a los militares y criticaba abiertamente lo expuesto en la sesión de las Cortes del día 26 de marzo. A lo largo de los artículos citados podemos comprobar que M. ‥ Manuela López de Ulloa fue siempre una fiel defensora de sus ideas y no se arredró pese a las duras críticas que recibió durante los tres años que colaboró con El Procurador General y La Atalaya de la Mancha.

\subsection{Carmen Silva}

La labor de Carmen Silva al frente de El Robespierre español como redactora principal es un hecho extraordinariamente relevante y sobrevenido por las circunstancias de la guerra. La biografía de esta mujer que destacó por su valentía está envuelta en el misterio. Nacida en la segunda mitad de 1700 en Lisboa, tomó parte activa en el conflicto al liberar en 1808 a las tropas españolas apresadas por Junot en la capital. Después de esto tuvo que refugiarse en Extremadura donde José Galluzo y Páez le concedió una pensión por los servicios prestados y le otorgó una licencia para abrir un estanquillo de tabacos. Allí conoció al médico Pedro Pascasio Fernández Sardinó al que se unió sin casarse. Tras la capitulación de Badajoz se refugiaron en la isla de León y allí comenzaron a publicar El Robespierre español, amigo de las leyes, o cuestiones atrevidas sobre España.

Las opiniones vertidas por Fernández Sardinó fueron consideradas desde el principio excesivamente avanzadas y revolucionarias, Ramón Solís (1971) indica que incluso e propio título causó un gran revuelo y que en seguida surgieron periódicos con la única finalidad de atacarle. Entre ellos hay que mencionar el Azote de Robespierre o el Cachidiablo andaluz. Ese espíritu exaltado lo lleva a criticar duramente a las tropas implicadas en la caída de Badajoz y especialmente al general Carrafa, al que considera el culpable del apresamiento de las tropas en Lisboa. Sus audaces palabras se repiten a lo largo de diez entregas y finalmente es denunciado y posteriormente encarcelado. Carmen Silva asumió la tarea de redactora jefe durante los meses que duró el encarcelamiento de Fernández Sardinó, desde el número XI al XXX, pero entonces en Cádiz. Las críticas contra El Robespierre español continuaron aunque a partir del cambio de editor tuvieron el aliciente de dirigir sus críticas contra un blanco femenino y atacaron a Carmen Silva 
con insinuaciones que no habrían hecho sobre su marido. En el "Vapulamiento de Robespierre" publicado en El redactor general (25 de octubre de 1812) se alude al hecho de que Silva y Fernández Sardinó no estaban legalmente casados y que los documentos de su boda eran una falsificación hecha por sus amigos para que pudiera visitarlo en la cárcel.

Durante los números en los que Carmen Silva actuó como redactora El Robespierre español también recogió textos firmados por Fernández Sardinó y muchos firmados por ella misma en los que se pide la libertad del marido y se defienden los derechos de la libertad de imprenta. Son estos textos los que más nos interesarán por ser de los pocos ejemplos de textos publicados por una mujer al frente de una publicación. A partir del número XI este hecho fue de dominio público puesto que se imprimió esta advertencia.

Interin que al editor de este periódico (que por su acendrado patriotismo se ha captado la benevolencia pública) se le pone en libertad para que se cure de sus males, y responda después a todas las censuras fundadas de los números denunciados y calificados, nadie extrañará que su esposa (que ya ha dado a la España un testimonio auténtico del amor que la profesa) la dé ahora otra prueba convincente de su afecto, publicando algunas obras del Robespierre Español, que por estar guardadas en su casa y no en el hospital, se salvaron de la nocturna agresión del 7 de agosto, día aciago, que no puede recordar sin horrorizarse. Deseara que merezcan, como hasta aquí, la aceptación de la patria de su esposo, que ya mira como suya la editora. Cádiz 27 de septiembre de 1811 (El Robespierre español, 1811: no 11, pp.161-162).

En el texto se hace referencia a las muestras de patriotismo dadas por "su esposa", es decir, su intervención en la liberación del ejército preso en Lisboa y a los sucesos ocurridos a su esposo, al que permitieron salir de la cárcel para curarse y estando en el hospital este sufrió una grave agresión. En el número XIII aparece de nuevo un capítulo de la Cartilla del ciudadano español, hasta su encarcelamiento se había ocupado su marido y ahora era ella la que la escribía. En él se recogía el artículo VIII correspondiente a los Derechos de la sociedad o fueros políticos y se utilizaba el formato de pregunta y respuesta como si se tratara de una entrevista en la que se van desgranando distintos aspectos relacionados con el tema del artículo. Tres números después del encarcelamiento del redactor vemos cómo Carmen Silva domina ya perfectamente el estilo de esta cabecera de la que ella se ha convertido en redactora. En los números siguientes continúa desgranando la Cartilla, así en la entrega XIV habla sobre la formación de la opinión pública, en la XV sobre la libertad de hablar y sobre la libertad de impresión. Este último tema desata su prosa y le dedica una buena parte de la entrega, qué duda cabe de que este asunto le preocupaba por tanto por motivos personales como profesionales. La libertad de prensa era un hecho desde 1810. Sin embargo, la censura también lo era; su propio marido estaba sufriendo sus consecuencias.

En el siguiente número se publica una carta dirigida a la editora del Robespierre por don José Díaz, que se hace eco de un artículo publicado en El Censor en el que se hacen numerosas críticas hacia su persona. Además comienza mostrando su sorpresa puesto que pensaba que los ataques habían cesado. Nada más lejos de la realidad Carmen Silva tuvo que soportar constantemente los insultos dirigidos hacia ella misma y su marido durante mucho tiempo. En esta carta a don José Díaz le sorprendía la virulencia del ataque en el que incluso ponían en duda su prendimiento “iAllá va eso! Pues si su esposa dice que le prendieron el 7 de agosto... Llamaron a Vd. Embustera; pues páguelos $\mathrm{Vd}$. con la misma moneda; diciéndoles que mienten. Dígales además que, digan lo que digan, no han nacido para escritores; bien que... para otra cosa de montañeses... tal cual; que para hacer algo bueno se necesita mejor chola que la suya... (El Robespierre español, 1811, no 14, pp. 212).

Sin duda uno de los ataques más iracundos que recibió fue el publicado en el suplemento al Redactor general el lunes 26 de octubre de 1812 titulado "Vapulamiento al Robespierre español, amigo de las leyes por mal nombre, en carta que escribía Zutano a Mengano" en el que tacha al editor encarcelado de estafador y explica en que se fundamenta: "ha estado siendo un atrevido estafador de la hacienda pública; porque mientras su arresto en el hospital, recetaba con auxilio de los suyos medicinas y refrescos para los enfermos de cierta sala: y las medicinas eran para la enferma mujer del Robespierre, y los refrescos para su tertulia" y proseguía insultando a su mujer: "Así el Robespierre con las gallinas, carne, carbón y demás perejiles sacaba más que suficiente para él, la Robespierra y agregados; y por su cálculo alzado, el hombre sensible que ha visto morir de hambre a los enfermos, hacía un gasto de más de dos pesos fuertes un día con otro de los nueve meses: bien que esta invención fue ingeniatura de su supuesta mujer" (El Censor, 1812, n.. 499).

Como puede verse, el autor de este texto no tiene suficiente con los insultos que les está dirigiendo como estafadores sino que cuando llega a ella no puede refrenarse y va más allá. Beatriz Sánchez Hita en su artículo "Las escritoras de la prensa de la Guerra de la Independencia vistas por sus colegas: ¿lucha de género o política?" incluye otro extracto del "Vapulamiento al Robespierre", ${ }^{5}$ en este texto se explica porque la llamó "supuesta mujer" añade que no está claro si es su legítima esposa o no. Lo cierto es que vivían juntos y que ella se presentó a las cortes y la Regencia como si lo fuera. El autor del "Vapulamiento" consideraba que esto era un desacato para el catolicismo y para la Regencia. Es necesario señalar que los insultos dirigidos a Fernández Sardinó

5 Este texto no está disponible para consulta, ella agradece a José Cosials de la Real Biblioteca de Madrid que se lo hiciese llegar. Indica que es de la misma fecha 25 de octubre de 1812 . 
se centran en su profesión como médico, como periodista y la mayor ofensa que recibe es la de estafador. Sin embargo cuando llega el turno de su mujer el hecho de que haya asumido la redacción de El Robespierre es "pecata minuta" comparado con el hecho de que viviese con un hombre sin estar casada. En este caso comprobamos una vez más cómo la doble moral señala acusadoramente a la mujer y olvida al hombre, para un hombre el peor delito es ser un estafador, para una mujer convivir con un hombre sin estar casada.

La Robespierra, permitámonos llamarla así, aprovechó la tribuna de la que disponía para contestar a los insultos. Sin embargo, hay que concederle que la mayor parte de la tinta la empleaba en defender a su marido y su labor al frente del periódico. Un ejemplo de esto lo encontramos en la entrega número XVI con el título: “Contestación de la esposa del editor del Robespierre española una carta escrita contra éste por D. D. de L. y C. y publicada en Valencia". La respuesta comienza con la explicación, por parte de Carmen Silva de cómo ha encontrado la carta en un viaje a Cádiz, y aprovecha este artículo para sincerarse: "Confieso que entre todos los varios papeles, con que han intentado calumniar y perder a mi patriota esposo sus malévolos enemigos, ninguno está escrito tan astuta y cuidadosamente como éste, y ninguno ha agotado todas las artes de la sofistería con más finura." (El Robespierre español, 1811: n. XVI, p. 241).

En el texto se extractaban algunos fragmentos de la última entrega que había firmado Fernández Sardinó y todo esto contribuye a acrecentar su enfado. Entre los argumentos que ella presenta están el patriotismo que es continuamente recalcado, su modestia y la forma que en la que entendía la revolución: "Pues sepan esos malévolos calumniadores para su confusión y vergüenza (si es que la conocen) que El Robespierre español ni aun siquiera descubrió a sus mayores amigos que era el editor de su aplaudido periódico, y que a los últimos números fue cuando lo supieron algunos amigos, a quienes fue posible ocultarlo." (El Robespierre español, 1811: n.ำ XVI, p. 246-247) y "El Robespierre quería dar a la revolución otro carácter muy opuesto, es verdad, pero era el carácter de rigor y de justicia; por el qual está clamando sin cesar la opinión pública" (El Robespierre español, 1811: n. ${ }^{\circ}$ XVI, p. 252).

A lo largo del tiempo que su marido estuvo encarcelado Carmen Silva publicó multitud de textos en los que aprovechaba el periódico para presionar a las autoridades y conseguir la excarcelación de su marido. En el número XXI recogía una carta de su marido en la que explicaba que llevaba cuatro meses esperando la carta del Consejo de Indias con la resolución, pero los papeles se han perdido. Seguidamente la redactora, en el número XXIII recogía el texto de la representación de la editora al Supremo consejo de Indias rogando la excarcelación de su esposo. En el siguiente agradecía al Consejo que hubiesen permitido la comunicación con su esposo por carta y finalmente en el número XXV expresaba de nuevo su gratitud a los altos cargos del Consejo porque su marido va a ser excarcelado. En todos los textos Carmen Silva hacía referencia al alto grado de patriotismo y a la valentía que ha mostrado siempre su esposo, los mismos valores que resalta en ella misma cuando ruega y hace valer sus méritos recordando su colaboración en la liberación de las tropas en Lisboa.

\section{Conclusión}

A lo largo del presente trabajo hemos recorrido la obra periodística de dos mujeres en la encrucijada de 1812. Dos mujeres muy distintas que se encontraban en bandos opuestos y que en todo momento se mantuvieron fieles a sus ideas aun cuando recibieron críticas y ataques mucho más duros y ofensivos por su condición de mujeres escritoras, en una época en la que se defendían los derechos y las libertades y en la que sus textos salieron del ámbito privado al público pagando por ello un alto precio y desapareciendo después. En el caso de $\mathrm{M}^{\mathfrak{a}}$ Manuela López de Ulloa en torno a su figura quedan muchos datos que desvelar aún, pero su nombre se pierde sin dejar rastro. De Carmen Silva sabemos que una vez liberado su marido éste recobró su puesto al frente de la publicación y aunque ella había demostrado sobradamente su capacidad para estar al frente de la publicación no volvió a aparecer su nombre firmando un artículo.

\section{REFERENCIAS BIBLIOGRÁFICAS}

Bravo, F., “Consideraciones sobre la mujer en dos periódicos gaditanos del siglo ilustrado: La Pensadora gaditana y la Academia de ociosos", VII encuentro de la ilustración al romanticismo, Coordinadora Cinta Canterla, Cádiz, Servicio de publicaciones Universidad de Cádiz, 1994.

Canterla, C., La Pensadora gaditana por Doña Beatriz Cienfuegos, Edición antológica de Cinta Canterla, Cádiz, Servicio de Publicaciones Universidad de Cádiz. 1996.

Cantos Casenave, M. y Sánchez Hita, B., "Escritoras y periodistas ante la constitución de 1812 (1808-1823) en Historia constitucional, $\mathrm{n}^{\mathrm{o}}$ 10. Págs. 137-179. 2009 http//:www.historiaconstitucional.com

Cantos Casenave, M., "Las mujeres en la prensa entre la ilustración y el romanticismo", en Cantos Casenave, M., Durán López, F., Romero Ferrer, A. (Eds.), La guerra de la pluma. Estudios sobre la prensa de Cádiz en el tiempo de las Cortes (1810-1814), Cádiz, Servicio de publicaciones de la Universidad de Cádiz, 2006-2008.

Chillón, Albert, Literatura y periodismo, Barcelona, Bellaterra, 1999.

Cienfuegos, Beatriz, La pensadora gaditana, Cádiz, Imprenta de Manuel Jiménez Carreño, 1786.

Dale, Scott, La Pensadora gaditana por Doña Beatriz Cienfuegos, Newark, Delaware, Juan de la Cuesta, 2005. 
Hartzenbusch,Eugenio, Apuntes para un catálogo de periódicos madrileños: desde el año 1661 al 1876, Madrid, Sucesores de Rivadeneyra, 1894.

----, Unos cuantos seudónimos de escritores españoles con sus correspondientes nombres verdaderos, Madrid, Sucesores de Rivadeneyra. 1904.

Palau y Dulcet, Antonio, Manual del librero hispanoamericano bibliografía general española e hispanoamericana desde la invención de la imprenta hasta nuestros tiempos con el valor comercial... librería anticuaria de A Palau, Barcelona, 1948.

Perinat, Adolfo-Marrades, Mª Isabel, Mujer, prensa y sociedad en España 1800-1939, Madrid, Centro de investigaciones sociológicas, 1980.

Ramos, A., “La vida cotidiana en el Cádiz de las Cortes”, en Cantos Casenave, M.-Durán López, F.-Romero Ferrer, A. (Eds.) La guerra de la pluma. Estudios sobre la prensa de Cádiz en el tiempo de las Cortes (1810-1814), Cádiz, Servicio de publicaciones de la Universidad de Cádiz, 2008.

Sánchez Hita, B., “La imprenta en Cádiz durante la Guerra de la Independencia y su relación con la prensa periódica”, en Cantos Casenave, M.-Durán López, F.-Romero Ferrer, A. (Eds.) La guerra de la pluma. Estudios sobre la prensa de Cádiz en el tiempo de las Cortes (1810-1814), Cádiz, Servicio de publicaciones de la Universidad de Cádiz, 2006-2008.

----, “Las escritoras de la prensa de la Guerra de la Independencia vistas por sus colegas: ¿lucha de género o política?", Revista HMiC, número VIII, 2010.

Solís, R.,,Historia del periodismo gaditano 1800-1850, Cádiz, Instituto de estudios gaditanos. 1971.

Sullivan, C., "Gender, text, and cross-dressing: the case of Beatriz Cienfuegos and La pensadora gaditana". Dieciocho, 18.1, 1995, págs. 27-47. 